\title{
PERFORMANCE APPRAISAL IN NIGERIAN INFORMATION CENTRES: AN EXIGENT NEED FOR SHIFT IN FOCUS AND METHOD
}

\author{
Abayomi Adedayo Omonori \\ Department of Project Management Technology, \\ School of Management Technology, Federal \\ University of Technology Akure, Nigeria
}

\begin{abstract}
Performance appraisal is a systematic process of evaluating and assessing the performance of employees in relation to their job expectations and responsibilities. Performance appraisals are performed in organisations for the purpose of ensuring that employees' duties are discharged in ways that will lead to the actualization of the goals of the organisation, giving the organisation a competitive edge over others. Studies have shown that PA (Performance Appraisal) is usually conducted annually in many organisations and are usually done with focus on the organisation and not the employees. This paper argues that performance appraisal should be shifted from organisation-focus to employeefocus as this is the only way employees' efficiency can be enhanced. The paper also discusses how information centres should properly carry out performance appraisal on their staff - a shift from the usual 360-degree, Human Resource Accounting Method, Behavioural Anchor Rating System (BARS), etc. - to interview format and how to turn this appraisal to employees' development and organisational productivity.
\end{abstract}

Keywords: Employees, Human Resource Management, Organisations, Performance Appraisal, Productivity

\section{INTRODUCTION}

Every organisation is established for specific purposes and to meet set objectives. In order to achieve these goals, proper management of available resources - human and material - is needed. Part of the ways to manage the human resources of any organisation is to ensure that employees are

\author{
Saheed Bidemi Ibrahim \\ Department of Communication and Language \\ Arts, University of Ibadan, Nigeria
}

committed to the missions and vision of such organisation in order to ensure productivity. Hence, the need for performance appraisal becomes imperative. Mwena and Gachunga (2014) aver that appraising performance is important because it helps to ensure that the organisation system is easily understood by employees and effectively put into action by managers. For every organization to constantly realize its set goals, it is imperative appraise employee's performance as a regular exercise (Kolawole, Kolawole, Adebayo \& Adegoroye, 2013).

Like every organisation, information centres also assess their employees' performance for various reasons. These reasons range from employee development, productivity of the employee, attainment of organisational goals, commitment of the employees to the organisation among others. Most times, performance assessment is conducted annually in every organisation. Its objectives are to ensure that every member of the staff is committed towards giving the organisation a competitive edge in the market. Also, it is a mechanism for staff development and future planning. Alqarni (2018:15) explains that "performance appraisal is conducted to evaluate the performance of the workforce in an organisation in relation to the roles and duties of each member of the workforce". He states further that PA is conducted in order to identify the right incentives to motivate workers in an organisation so as for them to be productive.

Whenever the phrase "information centre" is mentioned, the picture of a library comes up. This is because the library is the generally known information centre. All libraries are information centres but not all information centres are libraries. 


\section{International Journal of Engineering Applied Sciences and Technology, 2020 Vol. 4, Issue 11, ISSN No. 2455-2143, Pages 618-628 \\ Published Online March 2020 in IJEAST (http://www.ijeast.com)}

An information centre is a center designed specifically for storing, processing, and retrieving information for dissemination at regular intervals, on demand or selectively (Nieuwenhuysen, Alewaeters, \& Renard, 2005). Examples of information centre can be libraries, media houses, museums, information department of an organisation among others. Those who work in information centres are professionals in their respective fields librarians, reporters, cataloguers and so on. Information centres are responsible for gathering, storing and disseminating information either within an organisation or as a separate entity.

For information centres to be successful, Bancin, Rosalina and Nurminingsih (2018) posit that performance appraisal is one of the most needed requirements for successful business and HR policy formulation. This is because performance appraisal is a process that is useful in defining what the organisation pursues to achieve, creating understanding between the workers and the management, assessing loyalty, efficiency and dedication of employees to their duties and also identifying areas where development is needed so as to boost the productivity of both the workforce and the organisation. PA, according to Buckingham \& Goodall (2015), plays a very important role in employee management in an organisation because performance management leads to performance assessment and reveals its significance and applications. Performance appraisal is crucial because it involves metrics used to assess the productivity of the workforce in an organisation.

Boswell and Boudreau in Lu, Yue, Han and Chen (2018:2) identify two commonest types of performance appraisal - developmental and evaluative type. Appraisal for developmental purpose is conducted to assess the workforce in order to identify areas which developmental programmes can be used to boost productivity while the evaluative approach is used to basically assess the workforce in relation to the expectations require of them in their different roles in the organisation. Scholars over the years have proven that performance appraisal is for the benefits of the employee and the organisation. Its major purpose is for employee development and productivity because when employees are productive, the organisation will also be but an organisation cannot be productive if the employees are not.

However, Kolawole et al. (2013) reveal that studies have shown that PA practice in many information centres in Nigeria is always bias ridden and always evaluative focused. The designs, format, process, planning and implementation of PA are always faulty which has led to dislike for PA in many information centres in Nigeria. Modern appraisal should be futuristic: the purpose of the appraisal in an information centre or any organisation should focus on employees' development in order to enhance their capabilities, skills and ensure their productivity. Many organisations, especially information centres in Nigeria, only use performance appraisal to test productivity and not employee development (which is pre-requisite to productivity). There is no focus on turning employees to asset, all the management is concerned about is to examine if the organisation is productive or not. For example, in a radio station in Ibadan, appraisal was done mid-2018 on the traffic generated by all their programmes. It turned out that a presenter whose programme generated the least traffic was sacked. This is usually the situation anytime appraisal is done in this radio station. This is also the case in many organisations in the country banks, insurance companies, manufacturing companies, telecoms and also government parastatals in which appraisal is only done for evaluative purpose .

This paper therefore posits that there should be a shift from an evaluative approach to the human relations and developmental approach when carrying out appraisal on workers in information centres in Nigeria. The position of this paper is that it is only when workers are developed that their performance and productivity can improve. Information centres should not appraise performance to check the productivity of the organisation but to identify reasons responsible for workers' inefficiency and how these reasons can be solved through developmental programmes.

\section{PERFORMANCE APPRAISAL DEFINED}

Performance appraisal has been in existence for ages; long before the era of modernity. Mwena and Gachunga (2013) traced the origin of performance appraisal to the reign of second Caliph of Islam, Hazrat Umar between 634 to 644 A.D. Umar was reported to always appraise his appointees based on honesty and integrity before such person is fully appointed. When an officer of any status was found guilty of any form of negligence or dereliction from his duty, he would be removed from his office. Senyah, Coffie and Adu-Pakoh (2016) citing Landy, 


\section{International Journal of Engineering Applied Sciences and Technology, 2020 Vol. 4, Issue 11, ISSN No. 2455-2143, Pages 618-628 \\ Published Online March 2020 in IJEAST (http://www.ijeast.com)}

Zedeck and Cleveland, traced the origin of performance appraisals to the days of Aristotle. The earliest formal employee performance appraisal program is reported to have originated in the United States military establishment shortly after the birth of the republic (Lopez, 1968 in Senyah et al, 2016).

Performance appraisal in an organisation is a necessity. It is necessary to steer the ship of the organisation and its employees towards achieving the organisation goals. Organisation goals cannot be achieved without the workers being engaged and committed to the course. Peak organizational performance is dependent upon the performance of the individuals that make up the organization (Mwena \& Gachunga, 2014). HR Tool (2011:236) defines performance appraisal as "a formal system of review and evaluation of individual or team task performance". It is a process of examining, assessing and evaluating the level of performance of every employee in an organisation in relation to the expectations of the management in order to achieve organisational goals.

Mwena and Gachunga (2014) state that "performance appraisal is a periodic evaluation of the output of an individual worker that is measured against certain expectations by the organisation". The process involves observing and evaluating staff members' performance in the workplace with relation to pre-set standards. Citing Grote and Bacal, Alqarni (2018) holds that performance appraisal is a veritable mechanism that firms use to gauge the performance of their labour force and it enables managers and their subordinates to continually eliminate hurdles to work success. This definition reveals the purpose of PA. It shows that through appraisal, both the management and its workforce will be able to identify areas of development and factors militating against productivity in the organisation. This means that PA is not to conducted to downsize, but to optimise workers' efficiency.

Every organisation is a system with many subsystems (departments and individuals). Each of the sub-systems has certain role (or roles) it must play which are tied to the general goal of the organisation. Every employee in an organisation has specific roles, duties and responsibilities assigned to him or her. As such, there are certain levels of performance expected from each of them. Thus, appraisal is conducted in order to evaluate the level of performance by each employee in relation to the expectations of the management. According to John (2012), PA is essential for setting the objectives and quantifiable targets in an organisation. It is as well useful for drafting the standards and strategies for evaluation. This implies that PA is a necessity in an organisation to measure the output of the staff against the standard of practice set by the management of the organisation.

However, aside measuring employees' performance, appraisal, if well structured, can be a tool to identify individual staff's needs and how these needs can be linked to the goals of the organisation. Also, it is useful for future planning, training and development and to devise plans on how motivate and improve the performance of every worker in the organisation (Cole, 2012).

Senyah et al. (2016) state that performance appraisal provides the vehicle for increasing satisfaction, commitment, and motivation of the employee. Performance appraisals allow the organization to tell the employee something about their rates of growth, their competencies, and their potentials. As such, performance appraisal in information centres should help stimulate growth and motivation in the workers rather than provocation. When clear and reasonable performance appraisal metrics, measures and practices are used, it becomes useful for both the staff and the organisation.

However, despite all the benefits inherent in performance appraisal, it is sometimes disliked by employees. This is for no reason but what PA is used for in many organisations in Nigeria. According to Russell and Russell (2010), performance appraisal is often a negative, disliked activity. Supporting this, Houghton (2010) avers that managers do not like giving performance appraisal and employees do not like receiving it. This is also supported by a study by Kolawole et al. (2013) which finds that many HR managers in Nigeria see performance appraisal as "a necessary evil" that they cannot avoid: they appraise for the sake of doing it. They also found out that performance appraisal is subjective and lack objective measuring tools.

The dislike for performance appraisal is borne out of the fact that over the years, information centres and many organisations conduct employee appraisal in order to ascertain that the organisation is productive but attention is rarely given to employee development. Also, many workers feel dissatisfied 


\section{International Journal of Engineering Applied Sciences and Technology, 2020 Vol. 4, Issue 11, ISSN No. 2455-2143, Pages 618-628 \\ Published Online March 2020 in IJEAST (http://www.ijeast.com)}

after the appraisal as many feel they are not properly appraised and some lose their jobs after the appraisal. Errors such as leniency, halo effect, restriction of range, recent and contrast have been identified as common occurrence in appraisal system and these errors account for the dislike for performance appraisal. Many a time, appraisal ends up being just another annual task to be finished by the deadline. Academic librarians, journalists, presenters, cataloguers and other staff in information centres are the main hub of the centres, hence, they are faced with unique professional responsibilities that should be uniquely appraised based on their job descriptions and not some imported metrics outside their job descriptions.

John (2012) adds that appraisal sometimes ends up being just another annual task to be finished on schedule. It is done because it is necessary, and once done, it will be out of sight, out of mind. Many staff see performance appraisal as an irrelevant task because after the appraisal, nothing is heard in terms of feedback, development plan and other incentives to aid productivity. This is because appraisal is not done for the purpose of development but just for staff evaluation.

Simply put, performance appraisal can be likened to a test given to students to test their comprehension and understanding of what they are taught in class. This will reveal their weaknesses and strengths and show how the teacher(s) can ensure such student's improvement. Tests are not given to expel students but to gauge their performance. Therefore, PA should not be conducted as an exercise to just evaluate workers' performances in their respective roles or to measure organisation productivity, it should be conducted to identify the strengths and weaknesses of each staff and department, to identify the challenges they face $n$ their respective duties and how their efficiency and performance can be enhanced.

\section{RELEVANCE OF PERFORMANCE APPRAISAL IN INFORMATION CENTRES}

Literature has established that performance appraisal is a necessity in an organisation, especially information centres where the workers perform highly specialized and professional duties. It is a process that has, over time, been abused by bias towards the organisation against staff development. Many organisations misuse appraisal and only concern about organisation productivity and not staff development; this is the major problem identified by this paper. This section of the paper identifies the relevance of performance appraisal in information centres.

Alqarni (2018:17) identifies four goals of performance appraisal in an organisation. First, it helps to acknowledge the performance of the workforce in order to take decisions regarding compensation, promotion and layoff. This implies that PA is conducted for decision making regarding the staff of an organisation. It is a metric used to make decision regarding staff recruitment, development, promotion, compensation and dismissal.

Second, performance appraisal helps to identify staff strength and weakness of all staff members in an organisation and the need for appropriate incentives and developmental training. This has been established in this paper. PA is like a divination that reveals the "lacks" and the "haves" of the employees and what can be done to change the lacks to haves. Despite the fact that some organisations usually embark on staff training, many of them, especially in information centres, consider it a luxury they cannot afford. They will rather lay a staff off to get another than train him or her.

In addition, performance appraisal supports organisational goals by helping with system preservation. By this, PA helps to sustain and actualise the goals of an organisation. Lastly, the results of performance appraisal help to ascertain the effectiveness of PA and its tools in an organisation. PA helps to improve PA. a performance appraisal done in a particular quarter will be reviewed to identify the flaws in the process and how these flaws can be corrected in the next appraisal exercise.

Akinbowale (2013) adds that PA serves as a basis for employee evaluation and motivation. Also, it is a basis for employee development as it reveals strength and weakness of every appraised employee. Third, it is a veritable tool for organisation planning. The result of the appraisal can be used by the organisation to reshuffle staff, plan developmental programmes, delegate duties and strategise for productivity. The importance of performance appraisal are highlighted below: 
i. It is used for Human Resource planning in regards to employee relation, promotion and employee management in general

ii. Data from the appraisal can be used for recruitment and selection process. The performance of the existing staff can be used as benchmark for evaluating applicants before they are recruited into the organisation.

iii. It identifies areas in which development and training are needed in staff.

iv. It is used for employee career planning and development. Through the appraisal, each staff member in the information centre will know their areas of strength and weakness and the skills possessed by each of them.

v. It is useful for compensation programmes for employees in terms of promotion, pay adjustment, award and so on.

vi. Staff appraisal data are also used for decisions in several areas of internal employee relations, including promotion, demotion, termination, layoff, and transfer.

vii. The data from PA can be used to identify employee potentials for future purposes.

viii. Identify elements in the work atmosphere that help or hinder performance efficiency of staff

\section{HOW SHOULD STAFF AT INFORMATION CENTRES BE APPRAISED?}

Appraisal process has been one of the problems employees have with performance appraisal. In most organisations and at many information centres, performance appraisal is conducted once in a year, some dedicate a week to the process. This is a very wrong process. Performance appraisal in information centres should be a continuous process leading to the appraisal period. It shouldn't be just a week or a day process; it should be a continuous process in which each of its steps is directed towards employee development, productivity and attainment of organisation goals as identified by John (2012), HR Tool (2011), Ullah Khan (2013), Kolawole et al. (2013).

Another fault discovered in performance appraisal is the use of certain methods of appraisal such as Assessment Centre, 360-Degree Performance Appraisal, Human Resource Accounting Method, Behavioural Anchor Rating System (BARS), Management of Objectives among others. All these appraisal methods have been criticized for one reason or another. The most criticism against them is introduction of bias on the part of the appraiser (John, 2012; Kolawole et al., 2013; Mwena \& Gachunga, 2014). In addition to this, this appraisal methods are designed for general purpose and not for specific roles which vary from organisation to organisation.

No one knows what an employee faces in the discharge of his duty more than him. Therefore, he is in the best position to identify the challenges he faces on daily basis. The best form of appraisal is what we tag "Face to Face" appraisal method. This method involves the staff and the appraiser to sit in an interview setting. Box-ticking cannot help to properly appraise a staff. This is why many staff and managers dislike appraisal exercise. In this method, both parties discusses to understand and not to just listen. Appraisal should be interactive between the two parties. This will help both the organisation and the staff to identify certain hurdles blocking staff efficiency.

In addition, performance appraisal should be a continuous process and not a yearly routine. It should be a process that is inculcated into the day to day running of the organisation. This will be a continual reminder of the staff about their roles and organisational expectations. It will also serve a monitoring process to monitor the progress of the employees for optimization of performance. This is the best way to ensure productivity of both the employees and the organisation. Appraisal in information centres or any organisation should follow these steps:

i. Establish Standard Measures: The first step is to establish measures and standards of performance expected from every employee in the organisation based on individual roles and duties. These measures will differentiate between successful and unsuccessful performances. Nevertheless, these measures must be carefully selected with regards to achieving corporate goals (Watson \& Hill, 2009). The performance standards must be broken down in terms of traits, behaviors, competencies, goal achievement, and improvement potential (HR Tool, 2011) and must be drawn right before the employee is inducted into the organisation.

ii. Planning: Planning is the hub of any successful programme. It is the differential factor between successful operations and unsuccessful ones. In order for an organisation to achieve its 


\section{International Journal of Engineering Applied Sciences and Technology, 2020 Vol. 4, Issue 11, ISSN No. 2455-2143, Pages 618-628 \\ Published Online March 2020 in IJEAST (http://www.ijeast.com)}

objectives, planning of the appraisal process is an important subject. The manager plans for the realization of performance expectations, arranging for the resources to be available which are required for attaining the goals set. This is an enabling role (Kolawole et al, 2013). After this, factors such as work force development, improvements, promotions and assignments in managerial positions, persuasion and punishment, salary increase, personnel's performance feedback are all planned (Mwena \& Gachunga, 2014). As the employees discharge their duties, they are exposed to different trainings and developmental programmes. So, planning entails designing the job roles and who to occupy the identified roles in order to achieve the designed goals.

iii. Communicate Job Expectations: The set standards and measures must be communicated to employees. This should be done as the employee is inducted into the organisation and resumes duties. There will be constant reminder of these measures through various communication channels available in the organisation. The performance standard expected from the workers are communicated to them so for them to optimize their performance and tailor it towards the expectations of the management (HR Tool, 2011) on daily basis.

iv. Monitoring performance: Appraisal is not only conducted to see how employees fair in their duties but also to help them improve and develop skills needed to be productive in their duties. Performance appraisal is a continuous process, involving ongoing feedback. Even though performance is appraised annually, it has to be managed 'each day, all year long. By monitoring employing performance, such employee can be helped, enhanced, corrected and praised when the need arises and all these will lead to the appraisal period.

v. Appraisal: This is the period in which all the appraisal process will be put together to adjudge each employee based on the standard measures set at the beginning of the appraisal process. It involves documenting performance through observing, recalling, evaluating, written communication, judgment and analysis of data (Kolawole et al., 2013). The appraisal interview should be an interactive process between the appraiser and the appraised. This, as established earlier, will help to identify the factors that aid or inhibit the performance of the employees and help to identify where developmental training is necessary.

vi. Feedback: After the formal appraisal stage, a feedback session is desirable. Feedback is one of the major aspects of appraisal process. Workers should not be appraised and done with, as practiced in many organisations in Nigeria. Management at the information centres must engage in post-appraisal interview. How each of the workers fair in the appraisal must be communicated to them in order for them to know their strength, weakness and level of productivity for that year. In addition, areas of development and training will be communicated to every staff. Bekele, Shigutu, and Tensay (2014) states that employees become more dedicated when they receive prompt performance feedback on a regular basis after appraisal.

vii. Decision making: On the basis of appraisal and feed-back results, various decisions can be made about giving rewards (e.g., promotion, incentives, etc.) to employees who meet up with the set standards and developmental programmes for those who do not. The outcome of an appraisal system should be used for career development through motivation and training.

viii. Performance upgrading: In this stage, the appraisal system is reviewed for improvement and how to make the next appraisal better than the previous ones. Organisation management will look into areas and factors that pose hurdles to workers' performance such as working hours, welfare, working environment among others.

The aggregation of these steps in the appraisal process, if effectively and objectively carried out, will enhance the productivity of the staff in an information centre and will as well improve the productivity of the organisations.

\section{PERFORMANCE APPRAISAL AND EMPLOYEES' PRODUCTIVITY IN INFORMATION CENTRES}

Although there are mixed feelings as regards appraisal leading to productivity, literature has been able to establish a nexus between the two. Senyah, Coffie and Adu-Pakoh (2016), describes Performance appraisal as a systematic and periodic process that assesses an employee's job performance and productivity in relation to certain pre-established criteria and organizational objectives. It is also a method of estimating the level of achievement or 


\section{International Journal of Engineering Applied Sciences and Technology, 2020 Vol. 4, Issue 11, ISSN No. 2455-2143, Pages 618-628 \\ Published Online March 2020 in IJEAST (http://www.ijeast.com)}

success of staff in an institution with the objective of improving their performance. Therefore, an appraisal can be considered as an important factor in identifying the people's talents and capacities and its results can make them aware of advancements, plans and goals (Mwena \& Gachunga,2014) which will lead to employees' and organisational productivity.

John (2012) submits that an effective appraisal system is essential for human resources management in an organization. It encourages staff development and help increase productivity. Quality staff performance appraisal, if administered appropriately in a developmental sense, can become a channel to provide more learning opportunities for staff as well as powerful instrument in building a learning organization. This is an invocation that effective and employee-centred appraisal process will enhance productivity in an organisation. It creates an avenue for employees to know how they measure up in relation to the set standards and ways by which they can improve on it.

The study by Kolawole et al (2013) shows that some of the managers interviewed did not believe that performance appraisal leads to productivity. Most of the top managers interviewed described the process as subjective and it sometimes aggrieves some workers who are not positively rewarded after the appraisal. The study concludes that "performance appraisal system in Nigeria has a lots of problems but in spite of these problems, it has nothing to do with organizational performance of organizations especially when compare with other organizations" (p.10). this study shows that there is negative perception towards PA in the studied organisations. according to Mwena and Gachunga (2014), organizations should establish and adopt performance appraisal systems to aid opportunities for management to identify staff training needs, help employees meet performance targets, offer poor performers a chance to improve, help employees on time management through planning and setting of deadlines, enable managers to make informed decisions about promotions and assignments based on applicable facts, improve employee's synergies.

Kane and Lawler (2009) identify three major areas affected by performance appraisal in an organisation. First, PA affects the administration system in such a way that it facilitates administrative functions in an orderly manner. It helps to determine salaries, rewards, motivation and delegation of duties to the employees who are capable of handling certain duties. The second area is information. The informative function is fulfilled when the appraisal process furnishes management with relevant data about individual staff strengths and weaknesses. It showcases area where development is needed and it gives information about the strength and weakness of the organisation in term of human resources. Lastly, it performs motivational function by creating a learning experience that aims at improving workers' performance and productivity. All these put together will aid employee's productivity and also that of the organisation.

Mwena and Gachunga (2014) concludes in their study that organizations should appraise their employees often through utilized targets, accomplishments, organization goals, time management and efficiency for performance measure purposes as it would lead to increase in employee's productivity. From the findings, the study concludes that organizations should establish and adopt performance appraisal systems to aid in providing opportunities to the management in identify staff training needs, help employees meet performance targets, offer poor performers a chance to improve, help employees on time management through planning and setting of deadlines, enable the managers to make informed decisions about promotions and assignments based on applicable facts, improve employee's synergies.

According to Javed et al. (2013), PA is widely recognised as the most influential HRM practice, and it affects other important HR practices such as training, compensation and career advancement. Therefore, the end product of appraisal should be productivity. Appraisees, appraisers (managers) and the organisation at large reap the benefits of effective performance appraisals. Appraisees benefit in a number of ways; for example, they are well informed about what is expected of them and are able to set goals. They also gain a better understanding of their faults and strengths and can adjust behavior accordingly. In addition, appraisals create a constructive forum for providing feedback to workers about individual behavior, and for allowing workers to work on their weaknesses.

In the study conducted by Iqbal, Ahmad, Haider, Batool and Qurat-ul-ain (2013) on bank workers in Pakistan, it was found that performance appraisal leads to productivity with motivation playing a 
mediating role. That is, it is necessary for workers to be motivated in order for appraisal to lead to productivity. When workers feel demotivated after appraisal, then there cannot be any productivity from such workers. This is the main reason appraisal should not be used for demotion. Rather, it should be used for development. Workers who are not able to meet up with expectations should be trained and enhanced.

\section{HOW TO ENSURE PROPER APPRAISAL FOR PRODUCTIVITY AT INFORMATION CENTRES}

Ullah khan (2013:1) explains that performance structured system of evaluating an employee's job related behaviors and outcome to discover how and why the employee is presently performing on the job and he the employee can perform more effectively in the future so that the employee, organization and society can all benefit." In order to ensure that appraisal leads to productivity for any information centre, certain measures must be in place. Lu, Yue, Han and Chen (2018:4) aver that the developmental approach of performance appraisal is concerned with the worker's needs and motivation and it enhances productivity. Therefore, the number one purpose of performance appraisal at information centres must be for developmental purpose. Although, the evaluative approach is important, it must be tailored towards developing the workforce.

In order to ensure proper appraisal through appraisal interview, Wolff (2005) states that appraisers should be thoroughly trained in purpose and utilization of the performance appraisal system. The appraisals must understand the dynamics of an appraisal process and method used before appraising employees. A manager who does not understand the purpose and conduct of appraisal should not be made to appraise employees. Every appraiser must be trained in the act of appraisal.

The focus of the appraisal must be to train the appraisers, strengthen the staff communication and interactions, focus on training and development, redesign the tool, improve the accuracy of the assessment and ensure appropriate follow-up actions. These are ways by which appraisal can ensure productivity. Also, Bancin et al. (2018:8) founds that "the method of performance appraisal and employee job satisfaction cannot be separated in realizing better employee work performance". This implies that the appraisal method must be acceptable and understandable by the employees. This will breed acceptability and foster productivity.

Weis (2001) identifies three stages of ensuring productivity in an appraisal process. First, both the appraiser and the appraised must prepare for the appraisal process. In this stage, the appraiser prepares the standard and expectations of the organisation from the employees based on his or her job descriptions, required skills and qualifications. The employee on his own part identifies the problems and concerns he encounters in his position and what should be done to solve these problems. Their focus here is to analyse job performance, job responsibilities, employees' career goals, goals for improving performance, problems and concerns about the job. This is necessary in order to have a balanced assessment. Performance appraisal will not just be on the set standards without consideration for things that may hinder the optimum performance of the worker.

Second, managers and employees meet to discuss what they have prepared and to establish goals for the period before the next performance appraisal. It is important that the appraisal process should be an exchange and not a one-sided process. Both parties must be able to share their perceptions of the appraised's performance and discuss what each party have analysed. The last step is "the post-appraisal interview". This is the feedback stage where managers discuss the findings of the appraisal process and the decision taken by the management on the employee. Training, developmental programme, salaries, promotions and other factors can be discussed in this stage. It also can serve as a time for reiterating employee goals, duties and responsibilities to the organisation.

These three steps towards ensuring effective appraisal process are very important in information centres. This is necessary as workers will be able to identify the problem they face in their respective positions and also gives the organisation opportunity to identify areas in which the employees can be developed for productivity. Assessment of information workers should not just be for organizational goals alone but also for the 
development of the workers. After appraisal is done, an organization must ensure that the system evaluated for improvement so as to determine if the process is helping to drive the organisation and its staff towards achieving the organisation objectives and goals.

In addition, there must be a well-structured or desired appraisal method for staff at the information centres. Information centre workers perform specialized duties that require lots of skills and trainings, so, appraisal format that could rightly evaluate the various aspects of their job specifications should be used rather than any generic format or method of appraisal. The appropriate method we proffer is "Face-to-face" method.

For instance, In a study by Agyen-Gyasi and Boateng (2015) to evaluate the impact of performance appraisal on the productivity levels of professional and para-professional librarians in selected academic and research libraries in Ghana, it was discovered that "institutions practice performance appraisal on an annual basis as a way of promoting team work, reducing grievances, identifying employees' strengths and weaknesses and their training needs". But, there is no common appraisal format used by the institutions under study. Furthermore, they found that only the Head Librarians carry out the appraisals instead of the Line Managers who are always in touch with these employees on a daily basis. With these findings, appraisal cannot lead to productivity because the appraisers and the method used are faulty.

In Kanik's (2011) study conducted to reveal how and by whom staff appraisal efforts are carried out in university libraries in Turkey and how library staff perceive and consider staff appraisal, it was revealed that both directors and the staff of libraries have negative perception about performance appraisal method used on them in their respective information centres.

These studies by Ayen-Gyasi and Kanik's studies as well as many other studies have shown that performance appraisals are not properly conducted, hence, the negative perception about the process. According to Ullah khan (2013) Assessment should not be conformed to past performance alone. Potentials of the employee for future performance must also be assessed. Asamu (2013:1) recommends that for appraisals to yield the desired outcomes, the management should ensure that performance appraisal is carried out continuously, not only when it is time for promotion
Duraisingam and Skinner (2005) submit that for appraisal to be effective, it must first, be relevant and applicable to everyday work. Also, it must be considered as acceptable and fair by the workers. It should not be an enforced process but an acceptable one. In addition, there must be employee engagement in appraisal process. It is necessary to have a mutual collaboration between management and workers. This will give the workers sense of responsibility and belongingness. The workers will contribute to the process and aid employee management in the information centre.

Feedback is another way to ensure productivity in appraisal process. In a study by Senyah et al. (2016), it was revealed that $50 \%$ of the respondents received feedback information while the rest 50\% do not after appraisal. According to Mwena and Gachunga (2014), the results of performance appraisal should be used to discuss performance and progress of personnel in relation to goals. Performance strengths are recognized and weaknesses identified so that individual action plans can be developed to make the necessary corrections. Therefore, feedback must be given to every member of staff after the appraisal period. Mwena and Gachunga (2014) also add that "performance appraisal feedback affects the productivity of employees in the firm in that it enables the reviewing of employee's performance, improves cooperation with people outside their department, enables the staff to identify their skills and style and improve communications in the organization, enables the Supervisors/appraisers to take into account feedback provided by subordinates, enables the Supervisors/appraisers to assess feedback that comes from all around".

\section{CONCLUSION}

This paper, against the discussion on appraisal and productivity, concludes that appraisal in an information centre can lead to productivity. However, in order to ensure this, the focus of the management of the organisation must be to improve efficiency, effectiveness and productivity of the employees. Performance appraisal is a very useful tool in an organisation. If properly conducted and used, performance appraisal can lead to employee motivation which will lead to productivity.

In an information centre, employees should be appraised in order to identify areas where there is need for development and other management functions. It should be used to motivate workers and 


\section{International Journal of Engineering Applied Sciences and Technology, 2020 Vol. 4, Issue 11, ISSN No. 2455-2143, Pages 618-628 \\ Published Online March 2020 in IJEAST (http://www.ijeast.com)}

not be focused on improving the productivity of the information centre with neglect for the employees because without developing their skills and capabilities, information centres cannot be productive.

For appraisals to yield the desired outcomes (productivity), it is recommended that, the management should ensure that performance appraisal should be a continuous process and not only when it is time for promotion or disengagement. Also, it should be used to train the appraisers, strengthen the staff communication and interactions, focus on training and development and ensure proper planning for the management. Information centres consist employees with specialized skills and duties. Therefore, the appraisal method to be used for each role must be specifically designed to appraise workers in that role. No generic format should be used for the entire staff as this will bring ineffective appraisal to the process. Employees should be engaged in the process because information centres with engaged workforces have also reported less absenteeism, more engagement with customers, greater employee satisfaction, less mistakes, fewer employees leaving, and naturally higher productivity.

In addition, clear guidelines and effective training system should be developed for appraisers to reasonably report the strength and weaknesses of the appraised and make logical and fair recommendation as to how the appraised can be assisted in an improvement plan. This paper also recommends that the best way to appraise staff at information centres is through appraisal interview (a face-to-face method between the appraisal and the appraised) which is done after the appraisal measures have been set and communicated to the employees and they have been monitored over time and guided over time.

The appraisal interview is like the end product of the real appraisal process before feedback is given after. This method allows the workers and the appraiser to engage in one on one interaction to discuss the findings noticed in the course of the appraisal process. It gives the workers opportunity to identify constraints and hurdles they encounter in the course of discharging their duties and make input to HR process.

\section{ACKNOWLEDGEMENT}

We sincerely appreciate all the librarians and information workers that granted us interview.

\section{REFERENCES}

[1] Agyen-Gyasi, K. and Boateng, M. S. (2015) "Performance appraisal systems in academic and research libraries in Ghana: A survey", Library Review, 64, 58-81.

[2] Akinbowale, M. et al. (2013). The impact of Performance Appraisal Policy on Employee Performance. A Case Study of Guaranty Trust Bank in Nigeria. Mediterranean Journal of Social Science 14(4).

[3] Alqarni, S. (2018). The Relationship between Perceived Performance Appraisal Effectiveness and Employee Turnover Intention in Saudi Banks (Master's Thesis), Western Sydney University, Australia.

[4] Asamu, F. F. ((2013). Perception of performance appraisal and workers' performance in Wema Bank headquarters, Lagos. Global Journal of Arts, Humanities and Social Sciences 1(4), 89-101.

[5] Bancin, W., Rosalina, S. S. and Nurminingsih (2018). Effect of the Performance Assessment of Work Satisfaction and Work Achievement of Non PNS Employees in Kemayoran Regional Public Hospital. International Journal of Management and Administrative Sciences (IJMAS), 6(3), 1-12.

[6] Bekele, A.Z., Shigutu, A.D., and Tensay, A.T. (2014). The effect of employees' perception of performance appraisal on their work outcomes. International Journal of Management and Commerce Innovations, 2(1), 136-173.

[7] Buckingham, M., and Goodall, A. (2015). Reinventing performance management. Harvard Business Review, 93(4), 40-50. Retrieved from https://hbr.org/2015/04/reinventingperformance Management.

[8] Duraisingam, V. and Skinner, N. (2005). Performance Appraisal. In N. Skinner, A.M. Roche, J. O'Connor, Y. Pollard, \& C. Todd (Eds.), Workforce Development TIPS (Theory into Practice Strategies): A Resource Kit for the Alcohol and Other Drugs Field. National Centre for Education and Training on Addiction (NCETA), Flinders University, Adelaide, Australia. 


\section{International Journal of Engineering Applied Sciences and Technology, 2020 Vol. 4, Issue 11, ISSN No. 2455-2143, Pages 618-628 \\ Published Online March 2020 in IJEAST (http://www.ijeast.com)}

[9] Houghton, A. (2010). "Performance Reviews: It's about 'How,' Not 'Why'," BusinessWeek Online (January 11, 2010): 11.

[10] HR Tool (2011). Performance management and appraisal. Massachusetts, Academic Press

[11] Iqbal, N., Ahmad, N. Haider, Z., Batool, Y. and Qurat-ul-ain (2013). Impact of performance appraisal on employee's performance involving the Moderating Role of Motivation. Arabian Journal of Business and Management Review, 3(1); August 2013

[12] John, O. I. (2012). Annual performance appraisal of practising librarians: A study of academic institutions in Nigeria. Arabian Journal of Business and Management Review, (5), Dec. 2012.

[13] Kane, J.S., \& Lawler, E.E. (2009), "Performance appraisal effectiveness: its assessment and determinants". In Staw, B.M. (Eds), Research in Organizational Behavior, JAI Press, Greenwich, CT, 1, 42578.

[14] Kanik, L. (2011). Performance Appraisal of Library Staff Working in Universities. New Trends in Qualitative and Quantitative Methods in Libraries, 323-330 (2011).

[15] Kolawole, T. O., Kolawole, I. T., Adebayo, A. A. \& Adegoroye, A. A. (2013). Appraisal System: A tool for performance in selected organisations in Nigeria. International Journal of Sociology and Anthropology, 5 (7), 249-261.

[16] Lu, H., Yue, A., Han, Y \& Chen, H. (2018). Exploring the Effect of Different Performance Appraisal Purposes on Miners' Organizational Citizenship Behavior: The Mediating Role of Organization Identification. Sustainability, 10 .

[17] Mwema, N. W. \& Gachunga, H. G. (2014). The influence of performance appraisal on employee productivity in organizations: A case study of selected WHO offices in East Africa. International Journal of Social Sciences and Entrepreneurship, 1 (11), 324337.

[18] Nieuwenhuysen, P., Alewaeters, G., \& Renard, S. (2005). A new role of libraries and information centers: integrating access to distributed electronic publications. Conference on Electronic Publishing. Brussels.
[19] Russell, J. \& Russell, L. (2010). “Talk me through it: The Next Level of Performance Management," (April 2010): 42-48.

[20] Senyah, M.M., Coffie, R. B. \& Adu-Pakoh, K. (2016). Assessment of the effectiveness of performance appraisal on work productivity: A case study of Kumasi polytechnic. Global journal of human resource management, 4(3), 1-15, May 2016.

[21] Ullah Khan, M. F. (2013). Role of Performance Appraisal System on Employees Motivation. IOSR Journal of Business and Management (IOSR-JBM) eISSN: 2278-487X. 8(4), 66-83.

[22] Watson, H. \& Hill, J. (2009). "What Gets Watched Gets Done: How Metrics Can Motivate," Business Intelligence Journal 14 (2009): 4-7.

[23] Weis, R. G. (2001), "Guidelines for effective and defensible performance appraisal", Personnel Journal, 60, 776-82.

[24] Wolff, C. (2005). Appraisals (1): not living up to expectations. IRS Employment Review. 828, 29, 9-15. 